\title{
Optimized method for TAG protein homology modeling: In silico and experimental structural characterization
}

\author{
Jyoti Singh Tomar and Rama Krishna Peddinti* \\ Department of Chemistry, Indian Institute of Technology, Roorkee-247667, Uttarakhand, \\ India \\ E-mail: rkpedfcy@,iitr.ac.in, ramakpeddinti@gmail.com
}

\begin{abstract}
The DNA glycosylases cleave $\mathrm{C}-\mathrm{N}$ glycosyl bond to release a free base and generate abasic sites concurrently. Function and structure of these enzymes in the pathogenic bacterium Acinetobacter baumannii and its closely related species are not well characterized. Inhibition of TAG enzyme is a promising drug design strategy against $A$. baumannii. Here optimized molecular modeling approaches were used to provide a structural scaffold of TAG. The recombinant TAG protein was expressed and purified to determine oligomeric state using size exclusion chromatography, which showed the existence of TAG protein as monomer (mwt $\sim 21 \mathrm{kDa})$. Secondary structure and substrate binding were analysed using $\mathrm{CD}$ are in good agreement with the in silico predictions. Near UV-CD spectrum shows the involvement of Tyr residues in substrate recognition. Molecular docking studies were performed to understand the molecular recognition interactions and this knowledge was used to identify the potent inhibitors using virtual screening. Residues crucial for DNA holding and enzyme catalysis are reconfirmed by the in silico mutational studies.
\end{abstract}

Keywords: BER pathway, 3-methyladenine, FoldX algorithm, HhH superfamily

\section{Introduction}

Acinetobacter baumannii is documented as an opportunistic, multidrug-resistant pathogen. It causes various diseases such as meningitis, pneumonia, cellulitis, bacteremia, endocarditis, osteomyelitis, corneal perforation and urinary tract infections [1-3]. Treatment protocols that are currently employed against $A$. baumannii infections appear to be inadequate, while resistance rates to present therapeutic options such as carbapenems, polymyxins are continuously rising. Therapeutic failure in multidrug resistant pathogens in the current scenario demands the detection of novel drug targets essential at the key steps of 
metabolic pathways to cure the infections caused by A. baumannii. Availability of whole genome sequence of $A$. baumannii [4] facilitates the identification of new non-conventional potential drug targets [5]. Here we have selected the 3-methyladenine DNA glycosylase (TAG) enzyme, a base excision repair glycosylase that recognizes and excises 3methyladenine (3mA) from DNA, thereby maintaining the genome integrity [6]. DNA bases are constantly damaged and modified by a variety of cellular mechanisms which obstruct vital processes such as DNA replication and transcription. To circumvent this problem, nature evolved many repair pathways in all organisms. For example, base excision repair of modified DNA base is performed by DNA glycosylases by the hydrolysis of $N$-glycosidic bond, resulting in the release of damaged base and leaving the sugar phosphate backbone intact [7]. In prokaryotes, removal of alkylated purine bases through $\mathrm{C}-\mathrm{N}$ bond cleavage is performed by two DNA glycosylases which are coded by two different genes viz., tag and alkA genes [8,9]. The enzymes namely TAG and 3-methyladenine DNA glycosylase II (AlkA), possess capacity to recognize subtle modification in base structure and remove them from the genome. TAG enzyme does not show evident primary sequence similarity with other DNA glycosylases due to which its phylogeny is still mysterious [10]. TAG is distinctive from AlkA in substrate specificity and its specificity preserves systematic and constitutive elimination of positively charged $3 \mathrm{~mA}$ bases [11]. Involvement of TAG enzyme in DNA repair pathway makes it crucial component for the survival of $A$. baumannii. The interesting fact about TAG is that it has no homologous protein sequences and gene in archaea, lower eukaryotes, yeast, and in mammals.

Alkylpurine DNA glycosylases have been shown to be essential for the survival of both eukaryotic and prokaryotic organisms. Due to its absence in humans, TAG can be considered as a potential target against $A$. baumannii. Lack of experimental structure for TAG enzyme motivated us for to perform in silico and experimental study to provide a structural scaffold theoretically. In this work, we incorporated RepairPDB module of algorithm FoldX with traditional homology modeling procedure to improve the structural quality of model $[12,13]$. The need of this extra step during homology modeling is addressed in the methodology and the results and discussion sections. Model energy is evaluated using the Stability module, which includes terms that have been found to be crucial in the definition of protein stability. Subsequently, to gain insight into the residues involved in the identification of a DNA lesion, their excision and in binding specificity, we performed the point mutations using Protein Design utility of FoldX. This demonstrates the specificity of respective interactions at molecular level with reference to the available 
structural data. The calculated free energy changes show a good correlation with the experimentally observed rate of substrate $3 \mathrm{~mA}$ excision. Theoretical findings were supplemented with the experimental validation of secondary structure and substrate binding studies. Furthermore, we summarize the prime structural and mechanistic characteristics of TAG with a special focus on the residues that play central role in its action. Finally, structure-based inhibitor virtual screening is performed to identify novel anti A. baumannii lead compounds.

\section{Materials and methods}

\section{Computational methods}

All computational analyses were carried out on Intel dual core based Microsoft windows XP professional workstation and 16 GB RAM.

\section{Homology Modeling of TAG}

The reliability of homology modeling depends on the structural similarities between target and the template selected. Thus, identification of correct homologue is decisive for the generation of accurate model. BLASTp was used to search homologous sequences of TAG protein from Protein Data Bank (http://www.rcsb.org) and the sequence with highest similarity was used as a template for the homology modeling [14-18]. Secondary structure prediction and sequence alignment was carried out using ESPript [19]. Homology modeling of the TAG was performed using one of the widely accepted 3D structure prediction program, Modeller9v12 [20]. Modeller constructs the model using a set of restraints derived from the query-template alignment and then energy minimization was done to decrease the violations of these restraints. Restraint-based modeling methodology is better and most flexible as different types of restraints and constraints can be easily incorporated in it. Restraints can be derived from template structure or from experiments like NMR and fluorescence. [21-23]. Initially, 50 models were generated and the model having minimum discrete optimized potential energy (DOPE) score and better structural parameters was chosen for the loop refinement using Chimera Interface.

\section{Model optimization using RepairPDB and evaluation}

In general, the first step in model evaluation is examination of structural folds. The accuracy of a fold is ensured by selecting the template optimally aligned with the query sequence. 
VERIFY3D is used to check the fitness of structure to the sequence [24]. Second basic characteristic of a good model is to have good stereochemistry, for that PROCHECK [25] and WHATIF [26] were used. These programs are widely used for the examination of proper protein stereochemistry, such as symmetry and geometry checks (chirality, bond lengths, bond angles, torsion angles, etc) and structural packing quality. The best model was selected and energy minimization was carried out using Chimera tool Minimize Structure. This was achieved with the steepest descent algorithm and conjugate gradient algorithm each, using step sizes 0.01 and 0.02 , respectively. Minimized model is evaluated for its structural quality using the above mentioned programmes.

Comparative study performed by Wallner and Elofsson on the widely acknowledged six modeling programmes (Modeller, SWISS-MODEL, 3D-JIGSAW, nest, Builder, and SegMod/ENCAD) concludes that Modeller performance is excellent in all aspects while it is inferior in terms of side chain quality [27-29]. Keeping the problem of the side chain quality in the mind, we used the RepairPDB module of FoldX to further optimize the model. Working style of the command RepairPDB explains how it improves the quality of the model. Initially, it identifies the residues having nonstandard torsion angles and exhibits van der Waals clashes or total energy. Then it mutates the selected residues to alanine and annotates side chain energies of the neighbouring residues. Again it mutates alanine to the original amino acid and recalculates the side chain energies of the same neighbouring residues. Residues having energy difference are explored for different rotamer combination to find new energy minima. Finally, all side chains are slightly moved to get rid of small steric clashes. In this way RepairPDB quickly removes the small local clashes, and saves computing time by decreasing the number of real rotamer searches. Repaired model is evaluated for its quality using the above mentioned programmes. Stability analysis of model and template proteins was performed using energy function of FoldX to compare and analyse the significance of the energy terms contributing to the stability of these proteins. Gibbs free energy of unfolding $[13]\left(\Delta \mathrm{G}\right.$, in $\left.\mathrm{kcal} \mathrm{mol}^{-1}\right)$ is calculated using the following equation:

$\Delta \mathrm{G}=\Delta \mathrm{G}_{\mathrm{vdW}}+\Delta \mathrm{G}_{\mathrm{solvH}}+\Delta \mathrm{G}_{\mathrm{solvP}}+\Delta \mathrm{G}_{\mathrm{wb}}+\Delta \mathrm{G}_{\text {Hbond }}+\Delta \mathrm{G}_{\mathrm{el}}+\Delta \mathrm{G}_{\mathrm{kon}}+\mathrm{T} \Delta \mathrm{S}_{\mathrm{sc}}+\mathrm{T} \Delta \mathrm{S}_{\mathrm{mc}}+\mathrm{T} \Delta \mathrm{S}_{\mathrm{tr}}$, where $\Delta \mathrm{G}_{\mathrm{vdW}}$ is summation of van der Waals contributions of all atom, $\Delta \mathrm{G}_{\text {solvH }} \& \Delta \mathrm{G}_{\text {solvP }}$ are the differences in solvation energy when going from unfolded to folded state, for non-polar and polar groups, respectively; $\Delta \mathrm{G}_{\mathrm{Hbond}}$ is the free energy difference of intra-molecular hydrogen bond to inter-molecular hydrogen bond, formation (with solvent); $\mathrm{T} \Delta \mathrm{S}_{\mathrm{mc}} \& \mathrm{~T} \Delta \mathrm{S}_{\mathrm{sc}}$ 
are entropy cost of fixing, the backbone in the folded state and side chain in a particular conformation [30]. The final model is superimposed with the template structure using pymol for calculating the backbone RMSD.

\section{Molecular Docking of substrate and virtual screening of Zinc database in TAG}

The ability of molecular docking to predict the structural configuration with optimized and favourable interactions between small molecule and the macromolecular structure is a valuable tool in drug design. Molecular docking was performed using Autodock4.0.2 [27] to reproduce the experimental homologous TAG-substrate/inhibitor complexes. This was undertaken to validate the performance of the software. High-throughput virtual screening (HTVS) programs such as PyRx are useful adjunct to the time consuming and expensive wet bench experiments necessary to discover new drug candidate. AutoDock Vina in PyRx 0.8 (Virtual Screening Tools) [31] is used, which takes receptor as a rigid structure to perform virtual screening. For virtual screening, we collected 550 compounds from ZINC database (http://zinc.docking.org) based on at least $60 \%$ structure similarity with the substrate $3 \mathrm{~mA}$. For this, a WebME structure drawing tool was used to draw the structure of $3 \mathrm{~mA}$ structure, and then searched (Feb-2014, ZINC ${ }^{12}$ ) against standard subset (all purchasable) of ZINC database (having $\sim 11,500,000$ compounds). Compounds were downloaded in SDF format and then converted into PDB format using Openbabel program. The repetition in compounds was checked using pymol and finally the library of 550 molecules was created. For the energy minimization of the compounds, we used the Steepest descent and Conjugate gradient methods prior to virtual screening. Screening parameters include Lamarckian genetic algorithm with energy evaluations 5000,000. Grid center was chosen by comparing with experimental complex 2OFI (Grid was centered at 52.147, 34.577, 18.358) near the active residues Tyr18, Trp21, Gln43 and Trp48. The grid maps (70_70_70 points) with $0.381 \AA$ spacing were generated by AutoGrid. After the screening, the top ten compounds showing highest binding affinity are analyzed to get more insight into the stabilizing interactions.

\section{Experimental methods}

\section{Gene cloning and vector construction}

The oligonucleotides for PCR amplification were purchased from Integrated DNA technologies Inc. (Coralville, IA). DNA gel extraction and PCR purification kits were 
ordered from Qiagen Inc. XL1-Blue strain of Escherichia coli was used for transformation and amplification of plasmids. Restriction enzymes $N d e \mathrm{I}$ and XhoI were purchased from New England BioLabs, Inc. E. coli BL21 (DE3) expression strain was used as a host for protein over expression and pET-28a vector were obtained from Novagen Inc. Madison, WI, USA. The genomic DNA of $A$. baumannii was used as the template for the gene amplification using the two primers (forward) 5' GATTCTCATATGATGAAAAC TCAACGCTGCGGATG3' and (reverse), 5' GATTCTCTCGAGTTATGAAGCTTTAAAT GACAATCATTTTC 3'. Presence of the restriction sites in the primers allowed the construction of recombinant plasmid, having the tag gene into the corresponding sites of the pET-28a vector. After amplification, PCR purification kit was used to purify the PCR product which was then subjected to double digestion with $N d e I$ and XhoI enzymes. The pET28a plasmid was also treated with the same set of restriction enzymes at $37{ }^{\circ} \mathrm{C}$ for $1 \mathrm{~h}$. The digested fragments separated on $1 \%$ low melting agarose gel were excised after completion of the run. Subsequently, fragments were eluted from the excised band using DNA gel extraction kit and ligated in the presence of T4 DNA ligase enzyme. Ligated PCRplasmid product was transformed into the E. coli XL1-Blue competent cells by the heat shock method [32]. Colonies obtained by selective growth of the transformed cells on LuriaBertani agar plates containing $50 \mu \mathrm{g} / \mathrm{ml}$ of kanamycin were picked up and grown overnight at $37^{\circ} \mathrm{C}$. Cloned plasmids were isolated using a MiniPrep plasmid isolation kit and screened for the presence of the tag gene by restriction enzyme digestion (Supplementary Fig. SI-1). The integrity of the resulting plasmid, pETHis6-TAG, was confirmed by sequencing in both directions using $\mathrm{T} 7$ promoter and T7 terminator primers. Further, expression and solubility optimization experiments were done using the pEsupportTHis6-TAG plasmid.

\section{Optimization of expression and purification of the recombinant TAG protein}

The pETHis6-TAG having the tag gene of $A$. baumannii was transformed into $E$. coli expression strain BL21 (DE3). The expression and solubility of His-tagged TAG protein were tested by growing $5 \mathrm{ml}$ bacterial cultures in LB broth having appropriate antibiotics concentration. The overnight cultures were then diluted to $1 / 100$ with fresh LB broth supplemented with suitable concentration of antibiotics and incubated at $37^{\circ} \mathrm{C}$ till $\mathrm{A} 600$ becomes 0.6. The cultures were then induced with different concentrations of IPTG (1.0, $0.5,0.25,0.1 \mathrm{mM}$ ) and grown overnight at $37^{\circ} \mathrm{C}$ with shaking at $225 \mathrm{rpm}$. The expression of His6-tagged-TAG protein at $37{ }^{\circ} \mathrm{C}$ in E. coli BL21 (DE3) led to the formation of inclusion bodies regardless of the IPTG concentration used for induction. The expression 
was optimized by varying temperature $\left(37^{\circ} \mathrm{C}, 25^{\circ} \mathrm{C}\right.$ and $\left.19^{\circ} \mathrm{C}\right)$, the IPTG concentration for the induction of expression $(0.05,0.1,0.2,0.4,0.5,0.7$ and $1.0 \mathrm{mM})$, and $\mathrm{pH}$ of the media $(6.0,6.5,7.0,7.5,8.0)$. Cells were harvested by centrifugation at $7000 \mathrm{rpm}$ for $6 \mathrm{~min}$ at $4{ }^{\circ} \mathrm{C}$. Cell pellets were re-suspended in $5 \mathrm{ml}$ of $50 \mathrm{mM}$ Tris buffer of $\mathrm{pH} 7.6$, and disrupted using Cell disruptor (Constant Systems Ltd, Daventry, England). Then expression and solubility confirmation was done by analyzing this induced lysed cell supernatant and the pellet on $15 \%$ sodium dodecyl sulfate poly-acrylamide gel electrophoresis (SDS-PAGE) with uninduced control lysed cell supernatant and pellet. Soluble protein was obtained by growing the transformed $E$. coli cell at $18{ }^{\circ} \mathrm{C}$ for $\sim 16 \mathrm{~h}$ after induction with $0.7 \mathrm{mM}$ IPTG in the media having $\mathrm{pH} 6.5$.

Purification steps of His-tagged TAG protein were completed at low temperature ( $4{ }^{\circ} \mathrm{C}$ ). Cell pellets obtained from a 1 liter culture were re-suspended in $25 \mathrm{ml}$ of buffer $\mathrm{A}$ (50 mM Tris- $\mathrm{HCl}$ (pH 7.6), $250 \mathrm{mM} \mathrm{NaCl}, 2 \mathrm{mM}$ EDTA and 5\% glycerol) and disrupted using a Cell disruptor (Constant Systems Ltd, Daventry, England). To separate the protein present in supernatant from the cell debris, lysate was centrifuged at 15,000 rpm for $45 \mathrm{~min}$ at $4{ }^{\circ} \mathrm{C}$. The supernatant was incubated for $45 \mathrm{~min}$ with Ni-NTA beads (GE healthcare), preequilibrated with buffer A containing $15 \mathrm{mM}$ imidazole. Elution was performed by running a gradient of 40-500 $\mathrm{mM}$ of imidazole and the fractions were analyzed by SDS-PAGE. Fractions containing pure TAG was pooled and dialyzed for 3-4 h against $1 \mathrm{~L}$ of dialysis buffer [20 mM Tris- $\mathrm{HCl}$ (pH 7.6), $100 \mathrm{mM} \mathrm{NaCl,} \mathrm{5 \%} \mathrm{glycerol]} \mathrm{containing} 2$ mM EDTA. Purity and oligomeric state of protein was confirmed by the size exclusion chromatography. Purified protein was concentrated using an Amicon Ultra-3 kDa concentrator and stored at $-80{ }^{\circ} \mathrm{C}$. The yield and concentration of purified His-tagged TAG was measured using a BioRad protein-assay kit with bovine serum albumin as a standard.

\section{Circular dichroism}

The circular dichroism (CD) spectra were measured on Chirascan Circular Dichroism Spectrometer (Applied photophysics Ltd, Surrey KT22 7PB, UK). The scan speed was 50 $\mathrm{nm} \min ^{-1}$ with $1 \mathrm{~nm}$ bandwidth, $0.5 \mathrm{~nm}$ wavelength steps and an average time of $3.0 \mathrm{sec}$. For the far UV-CD measurement, wavelength range of 190 to $260 \mathrm{~nm}$ and for the near UV$\mathrm{CD}$ measurement, the wavelength range of 260 to $320 \mathrm{~nm}$ were taken with three accumulations in a quartz cell with nominal path length of $1 \mathrm{~mm}$. Protein sample is dialyzed for $4 \mathrm{~h}$ in $\mathrm{CD}$ buffer containing $25 \mathrm{mM}$ sodium phosphate buffer of $\mathrm{pH} 7.6$ and $100 \mathrm{mM}$ 
$\mathrm{NaCl}$. After dialysis, the contents were centrifuged at $14,000 \mathrm{rpm}$ for $30 \mathrm{~min}$ and then filtered through 0.1 to 0.2 micron filters to reduce light scattering. Protein samples at concentration of $1 \mathrm{mg} / \mathrm{ml}$ were used for recording spectra and the same buffer was used as the blank. For each sample, collected scans were averaged, and then the baseline corresponding to the buffer was subtracted to obtain the final spectra. The final spectra were analyzed using the programs CDNN [33]. Effects of variable concentrations of substrate $(3 \mathrm{~mA})$ and $\mathrm{Zn}$ binding on the secondary and tertiary structure of TAG were determined by incubating the protein with $10,50,100,200,300,400,500$ and $600 \mu \mathrm{M} 3 \mathrm{~mA}$ and 50,100 $\mu \mathrm{M}$ of $\mathrm{ZnCl}_{2}$ for $4 \mathrm{~h}$ at $4{ }^{\circ} \mathrm{C}$ followed by the far UV-CD and near UV-CD measurements.

\section{Results and discussion}

\section{Sequence alignment and secondary structure prediction of TAG}

BLAST against the PDB database illustrated that TAG shares at least 53\% sequence identity with TAG of Salmonella typhi (PDB: 2OFK) and E. coli (PDB: 1LMZ) (Supplementary Table SI-1). TAG of $A$. baumannii is 186 amino acid long, shows 56\% primary sequence identity and $65 \%$ similarity with 183 amino acid long TAG of Salmonella typhi (PDB: 2OFK resolution $1.50 \AA$ ). Therefore, $2 \mathrm{OFK}$ is considered as a suitable template for homology modeling (Fig. 1). Amino acid sequence of the model indicates that it belongs to 3-methyladenine DNA glycosylase I enzyme, which is also supported by the conserved domain search. Since TAG belongs to superfamily helix-hairpin-helix (HhH) of DNA glycosylases, the HhH motif of TAG is also used for DNA binding in a sequenceindependent manner like other protein members of this superfamily [34]. Fig. 1 represents sequence alignment of the target and template TAG using ESPript. Inspection of sequence alignment reveals higher sequence similarity in the N-terminal region. The multiple sequence alignment result also demonstrates that residues near $\mathrm{N}$-termini are relatively conserved (Supplementary Fig. SI-2). It is also known from the literature that functional cavity is mainly mapped by the aromatic residues present near the N-terminal region. Among all the secondary structures [35] the residues present at the helices $\alpha 1, \alpha 2, \alpha 3, \alpha 4$ and the loops formed from helices $\alpha 1 / 2, \alpha 2 / 3, \alpha 3 / 4$ and $\alpha 9 / 10$ are more conserved. The loop residues, present between helices $\alpha 5 / 6$ are not well conserved, but similar nature of these residues in $\mathrm{HhH}$ family member might be suggestive of similar functional role. In the TAG from $S$. typhi as well as in A. baumannii, the residues Cys181 and Cys4 are conserved and both are present side by side in space to make zinc binding motif. Zinc binding domain 
tethers the $\mathrm{N}$ and $\mathrm{C}$ termini and this domain is not found in its closely related bacterial enzymes like AlkA and MagIII, of the same $\mathrm{HhH}$ superfamily. The C-terminal residues contribute in DNA holding during repair process through hydrogen bond interactions to the backbone phosphate and participate in the formation of zinc snap motif.

\section{Validation of modelled structure and optimization of model using FoldX RepairPDB}

Verification of model quality and estimation of the probability and magnitude of errors are critical in advancing the state of homology modeling [36-39]. As discussed in the methodology section, for optimization, the model has been passed through repair function of FoldX algorithm. The repair function can be considered as one of most successful combinatorial optimization algorithms in generating rotamer ensemble having favourable conformations. Assessments of the stereochemical parameters and 3D-1D score for fitness of model structure to query sequence illustrates that quality of model generated by the Modeller9v12 is not optimal (Table 1). Similarly, structure validation reports of the energy minimized model were also found disagreeable (Table 1), which may be due to the drifting away of the coordinates from the template coordinate during energy minimization. The quality of FoldX repaired model is also checked using above mentioned validation programs and interestingly the model quality was found to be optimal and comparable to template structural parameters (Table 1). This demonstrates that repair function is successful in optimizing model parameters. Ramachandran plot of the optimized model structure shows that more than $91.1 \%$ of the residues have $\varphi$ and $\psi$ angles in the core regions, $8.9 \%$ residues in the allowed regions, with no residues in the generously allowed and disallowed regions. The percentage of residues having averaged 3D-1D score $>0.2$ was improved from 74 to 88 by the repair function revealing successful fitting of rotamers performed by the same. RMSD value for the model is calculated and found to be $0.19 \AA$ by keeping the template structure $2 \mathrm{OFK}$ as reference. These results suggest that quality of the generated TAG model (id: lldbpmi6whn4dfl5v; Model Archive doi: ma-a6bjp) is good and sufficiently accurate for further molecular modeling studies.

The FoldX stability analysis upon execution produces Gibbs energy of folding decomposed in various energy terms; it is calculated as difference in free energy between folded and unfolded states. The values for energy terms $\Delta \mathrm{G}_{\mathrm{vdW}}, \Delta \mathrm{G}_{\text {solv }} \Delta \mathrm{G}_{\text {solvP }}$ and $\Delta \mathrm{G}_{\text {Hbond, }}$ of each atom type, have been derived from experimental data while the entropic costs $(\Delta \mathrm{Smc}$ and $\Delta \mathrm{Ssc})$ are derived from theoretical estimation. Values of different energy terms 
calculated for the repaired TAG model and template pdb structure are given in supplementary information (Supplementary Table SI-2). Contributions coming from destabilizing energy terms in the model are found to be balanced by favourable energy terms. Molecular interactions contributing to the favourable energy are dominated by $\mathrm{H}$ bonds, hydrophobic and van der Waals, while entropic loss and van der Waals clashes are found to be main destabilizing interactions in the model. Stability analysis of template $S$. typhi TAG is also performed, to comparatively judge the model quality. Interestingly the energy terms of the repaired model are near to template $2 \mathrm{OFK}$.

\section{Comparative structural analysis of model with TAG of S. typhi}

The current TAG model is compared with the experimental structure of TAG S. typhi, as it exhibits structural as well as functional homology with our model. Model is consists of ten $\alpha$-helices, two 310 -helices and one parallel $\beta$-sheet, sequence of secondary structure in the model is $\alpha 1 \alpha 2 \alpha 3 \alpha 4 \eta 1 \alpha 5 \alpha 6 \alpha 7 \alpha 8 \beta 1 \eta 2 \alpha 9 \alpha 10 \beta 2$. The secondary structures $\alpha 1, \alpha 2, \alpha 3, \alpha 4$ and loops formed from helices $\alpha 1 / 2, \alpha 2 / 3, \alpha 3 / 4$ and $\alpha 9 / 10$ are more conserved. These secondary structures play an important role in DNA binding and base excision mechanism and this conservation in secondary structure elements elucidate the closer structural-functional resemblance of model with template (Fig. 1). The analysis of secondary structure shows that the enzyme consists of $62.4 \%$ helix, $3.2 \%$ sheet, $8.6 \%$ turn and $25.8 \%$ coil structure. Residues making plug and wedge [40] are present on the same secondary structure element ( $\alpha 2 / 3$ loop) of the model (contrary to the observation in other HhH glycosylases). Residues Gly43-Leu44 from TAG of S. typhi involved in conserved intercalation mechanism are significant for the interrogation of lesion in DNA during search process. These residues make special interactions leading to a $60^{\circ}-70^{\circ}$ bend in the DNA, helping the TAG enzyme in gaining access to the modified base without any significant conformational changes. These residues are known to play pivotal role in holding DNA during enzyme catalysis [41] and are also present at $\alpha 2 / 3$ loop (Gly45-Leu46) of the TAG model. The $\mathrm{Zn}^{2+}$ binding motif is conserved and it tethers the $\mathrm{N}$ - and $\mathrm{C}$-termini. Cao and co-workers proposed that the zinc snap motif of TAG contributes for the stabilization of $\mathrm{HhH}$ domain in a way similar to that of protein-protein interaction present in larger $\mathrm{HhH}$ superfamily members [42]. In the model, $3 \mathrm{~mA}$ binding pocket is located at the interface between the $\mathrm{Zn}^{2+}$ binding domain and helical domain with $\mathrm{HhH}$ motif. In $\mathrm{TAG}, \mathrm{HhH}$ motif is known to contribute $\sim 50 \%$ of polar interactions made with DNA backbone [41] and the residues involved in such interactions (except Ile161) are present at the same secondary structure in the model as in template TAG 
enzyme (Fig. 1). The electron-rich aromatic binding pocket of TAG derives a significant amount of binding energy through $\pi-\pi$ stacking interactions with electron-deficient alkylated base (3mA) [9]. The electronegative pocket in the TAG provides the compatible environment to positively charged 3mA (Supplementary Fig. SI-3A). The $3 \mathrm{~mA}$ found to form two H-bonds with Glu38 residue and one H-bond with Tyr16 in experimental S. typhi TAG. These residues work as adenine recognition motif, homologous to Glu37 and Gln 182 residues of the MutY adenine glycosylase enzyme. High quality function score $(\mathrm{Q}$ score $=$ 0.94) from PDB-efold, one of the well known structure alignment programs, affirms resemblance between the fold of the aligned molecules (Table 1). Superposition of S. typhi TAG and model structures shows that the protein backbones and positions of active site residues are superimposing well (with an RMSD of $0.16 \AA$ for all main-chain atoms and $0.10 \AA$ for active site atoms (Fig. 2A and Fig. 2B). The bond angles and bond lengths between the relevant amino acids were analysed and no considerable difference was observed except for Tyr15 Supplementary Fig. SI-3B).

\section{Condition optimization for expression of TAG protein and purification of TAG protein}

The expression of His6-tagged-TAG protein at $18{ }^{\circ} \mathrm{C}$ in E. coli BL21 (DE3) for $\sim 16 \mathrm{~h}$ after induction with $0.7 \mathrm{mM}$ IPTG in the media having $\mathrm{pH} 6.5$ resulted in expression of recombinant $A$. baumannii TAG protein in soluble form (Supplementary Fig. SI-4). The protein was purified by Ni-affinity chromatography where an imidazole gradient was used for eluting bound proteins. His-tagged protein was eluted from the column at an imidazole concentration of $\sim 200 \mathrm{mM}$. The purified TAG protein fractions are collected and to evaluate purity, collected fractions were analyzed on a 12\% SDS-PAGE gel which was stained with Coomassie blue. It is estimated that the purity of the protein fractions are $>95 \%$, corresponding to $\sim 21 \mathrm{kDa}$ band (Supplementary Fig. SI-5). Fractions having TAG protein were subjected to 3-step dialysis in phosphate buffer for the buffer exchange. Purified protein was concentrated to about $1 \mathrm{mg} / \mathrm{ml}$ and concentration of the purified protein was $\sim 10 \mathrm{mg}$ per litre of culture. Furthermore, to remove the minor impurities present in the protein, and to identify the oligomeric state of the protein in the solution, gel filtration chromatography was performed using Superdex-200 26/60 prep grade gel filtration column. From the column TAG was eluted as single peak at volume $90.45 \mathrm{ml}$ corresponds with molecular mass of $\sim 21 \mathrm{kDa}$, which confirms the presence of TAG protein as monomer in the aqueous solution (Fig. 3A). The very small second peak, obtained at $\sim 94 \mathrm{~mL}$, might be 
of impurity present in the solution along with the protein obtained after affinity (Ni-NTA) chromatography. The fractions were analyzed using 12\% SDS-PAGE, which confirms the presence of pure TAG protein in the aqueous solution (Fig. 3B). Fractions having pure protein are concentrated to $1 \mathrm{mg} / \mathrm{ml}$ for the $\mathrm{CD}$ experiments and were stored at $4{ }^{\circ} \mathrm{C}$.

\section{Secondary structure and substrate binding analysis using CD spectroscopy}

The $\mathrm{CD}$ is acknowledged as a valuable biophysical technique for examining the proteins structure in solution. It is considered as an excellent method for the speedy evaluation of secondary structure, conformational changes and binding properties of proteins. In addition to the several aspects of TAG discussed in previous sections, the secondary structure and the binding properties of TAG with the substrate were evaluated with the help of $\mathrm{CD}$ experiment. Amide chromophores, the building blocks of protein backbone, are aligned in arrays, their optical transitions split into multiple transitions due to exciton interactions. These interactions yield distinct CD spectra for different types of secondary structure and these characteristic spectra have been utilized in the quantitative estimation of secondary structure and monitoring of protein folding and unfolding. Secondary structure of TAG was studied using far-UV circular dichroism and representative CD spectra of TAG are presented in Fig. 4A. The characteristic minima (209 and $222 \mathrm{~nm}$ ) of $\alpha$-helical structure are clearly visible in the CD spectrum (native) of the TAG. The spectral data were analyzed and deconvoluted by the program CDNN which yields a secondary structural content of $62.2 \% \pm$ $10 \% \alpha$-helix, $3.1 \% \pm 1 \% \beta$-sheet, $6 \% \pm 3 \% \beta$-turn, and $28.7 \% \pm 7 \%$ random coil. This is very close to secondary structural content obtained in theoretical prediction.

Structural changes in protein caused due to ligand binding are essential for the mechanism of action and regulation of biological activity. The $\mathrm{CD}$ provides an experimentally convenient means of detecting such changes at different spectral regions. In addition, here $\mathrm{CD}$ is used to access the ligand concentration over which spectral changes take place and the extent of the change. The addition of substrate $3 \mathrm{~mA}$ to the enzyme TAG resulted in significant change in the intensity of $C D$ spectra, such as increase in the signal around $222 \mathrm{~nm}$ as well as at $208 \mathrm{~nm}$ was noticed (Fig. 4A). The band at $222 \mathrm{~nm}$ is known to arise from strong H-bonding environment of $\alpha$-helices and is relatively independent of their length. Due to this reason, various concentrations of substrate binding at CD signal $222 \mathrm{~nm}$ are monitored (Fig. 4C) and the complete range of wavelength as a function of concentration is also shown in Supplementary Fig. SI-6. The Fig. 4A shows how binding may induce protein to be more helical means binding increases the compactness in the three-

dimensional structure of the TAG. The analysis through CDNN program shows that after 
substrate binding, helical content increases from $62-91 \% \pm 10 \%$ and some decrease in the $\beta$-turn and random coil content was noticed. The ellipticity at $222 \mathrm{~nm}$ as a function of substrate concentration showed that the ellipticity decreased $\sim 6$ times on saturation as compared to native TAG. The shape of graph in Fig. 4C represents the characteristic graph of protein refolding [43]. A large increase in the helical content was observed on substrate binding, which may not be only due to substrate binding, since the recombinant enzyme TAG probably exists as the molten globule state in solution and binding of substrate may induce protein folding to craft proper-shaped active pocket. The change in ellipticity can be used to determine the substrate binding constants, the increment in the ellipticity is almost equal at the substrate concentration $200 \mu \mathrm{M}-600 \mu \mathrm{M}$ [44]. The protein folding unfolding study is also carried out as a function of temperature, which indicates that the TAG unfolding is a two-step process (Fig. 4D).

The changes in shape and magnitude in near UV-CD spectra of protein depend upon the nature of each type of aromatic amino acid present, and their environment (H-bond, polar groups). It is important to understand the role of each active site residue of the protein. The change in tertiary structure is caused by the substrate binding (Fig. 4B) and it is clear from near UV-CD spectra that the environment of pocket is modified due to substrate binding. On titration with substrate, a significant change of positive shift in the near UV-CD spectrum was identified, especially in $270-285 \mathrm{~nm}$ region of the Tyr residue. From these spectral changes, it can be inferred that local tertiary structure of Tyr in the protein is affected upon substrate binding. The molecular docking analysis also supports the interaction of substrate with residues Tyr15 and Tyr18 in the binding pocket through Hydrogen-bonding interactions (Fig. 5C). Similarly, the spectral changes in the tyrosine region attest that the binding of $3 \mathrm{~mA}$ affects the local tertiary structure of Tyr aromatic side chains significantly. We presumed that $\mathrm{Zn}$ binding by TAG would kick off or engender conformational changes on TAG and hence the CD spectra of TAG were measured to see the effect of $\mathrm{Zn}(\mathrm{II})$. Slight perturbation of the CD spectrum was observed along with increase in the ellipticity as compared to native (Supplementary Fig. SI-7). This change in spectra shape and ellipticity indicate that binding of zinc resulted in slight reorganization in the secondary structure adding stability of overall TAG structure. Stivers and coworkers stated that zinc snap motif allows the TAG family to efficiently stabilize the HhH structure without additional protein scaffolds observed in closely related families [42, 45]. 


\section{Molecular docking analysis of substrate and virtual screening to identify inhibitors against TAG enzyme}

As the very first step, molecular docking of co-crystallized ligands was performed in the macromolecular structures. The purpose of this redocking was to examine whether molecular docking simulation using Autodock4 are able to reproduce the binding pose as reported in experimental TAG protein complexes and to characterize the molecular recognition interactions. Homologous TAG protein complexes present in the PDB were also used in redocking procedure to understand the molecular recognition interactions. RMSD values are calculated by keeping the experimental pose as reference (Supplementary Fig. SI-8). In redocking, the atomic structures from a co-crystal are used as starting coordinates. The RMSD values for $3 \mathrm{~mA}$ is $1.67 \AA$ (Fig. 5A) and for other experimental complexes are approximately $2 \AA$. Theoretical binding energies, RMSD values and $\mathrm{IC}_{50}$ values for all the redocked ligands are given in Table 2. Theoretical binding energies for 2OFI, 1PU8 and $1 \mathrm{P} 7 \mathrm{M}$ are showing good correlation with their experimental IC50 values. This indicates that autodock is successful in discriminating these experimental complexes. Further, analysis of binding sites, done for redocked $3 \mathrm{~mA}$ to examine the molecular interactions, indicates that the residues Tyr16 and Tyr13 are involved in the direct hydrogen bonding and play crucial role in tuning of docked pose (Fig. 5B). Other contribution for binding is coming from van der Waals interactions and $\pi-\pi$ stacking with a conserved Trp side chain. However, the experimental conformation crafts three H-bonds; one with Tyr16 and two with Glu38 (Fig. 5A, cyan coloured). Molecular docking analysis of the substrate $3 \mathrm{~mA}$ with the model was also performed which shows that docked pose is different from the experimental pose. However, the docked pose of $3 \mathrm{~mA}$ forms H-bonds with the residues Tyr15 and Tyr18 of model (Fig. 5C). The possible reason for this difference in the docked pose of $3 \mathrm{~mA}$ in template as well as in model from experimental conformation might be due to the lack of conformational flexibility of receptor during molecular docking simulation. Experimental results (our CD data as well as literature data $[43,44]$ ) show that binding and removal of $3 \mathrm{~mA}$ is completed by the conformational change in the enzyme, which may help in optimization of substrate binding with enzyme (Fig. 5A, Green coloured).

The virtual screening has been successfully used as an adjuvant to high throughput screening approaches for the discovery and development of new compounds. In the present study, the information obtained about the molecular interactions between substrate and enzyme required for the optimal binding is used in the virtual screening. Here, all the 550 
compounds selected for virtual screening exhibited binding with target protein. The main objective of this part of work is to identify potent inhibitors of TAG enzyme using a combination of various in silico techniques like redocking of experimental complexes, virtual screening and ADMET. The top ten compounds based on binding affinity are summarized in Table 3, and these compounds are further analysed to inspect the active site residues and molecular interactions involved in binding to enzyme. Stabilizing interactions for the inhibitors are provided by the residues Trp8, Tyr18, Glu40, Gln43, Trp48 and Gln169, which are known to be crucial for catalytic activity using the experimental mutational study [41]. H-bonds, van der Waals and stacking interactions play crucial role in the binding of $3 \mathrm{~mA}$ and inhibitors. Finally, bound conformations of inhibitors having high binding affinity are superimposed to check the deviation in the binding poses (Fig. 5D). The evaluation of drug likeness score for these molecules was done using web server http://www.molinspiration.com/ (Table 3). It calculates the score as a complex balance between structural features and various molecular properties to determine whether the molecule taken for study is comparable to the well known drugs. The high value of the drug likeness score symbolizes the higher probability of a particular molecule to be active. Based on the score values, the compounds 4,6 and 7 qualify to be the better candidates for further experimental studies; binding pose of these inhibitors are similar with the substrate $3 \mathrm{~mA}$ and makes similar type of molecular interaction with the active site residues. Here we conclude that the compounds 4, 6 and 7 exhibit drug-like properties, and exhibit significant binding affinity and optimal molecular interactions with the enzyme TAG, and due to which these compounds could be used as competitive inhibitors. However, experimental enzyme inhibition assay is required to reconfirm the inhibitory potential. Synthesis of these compounds is in progress in our laboratory.

\section{Mutational studies of amino acid residues involved in the TAG enzyme activity}

To get more insight about amino acids directly or indirectly involved in TAG activity, we performed point mutations using Protein Design and Position scan utilities of FoldX. Generally mutations are performed in the wet lab to study the contribution of an amino acid on protein stability and functionality. Such site-directed mutagenesis in the wet lab is laborious and costly. Metz and co-workers [41] used twelve residues from TAG of S. typhi in their experimental study. Similarly, we also selected those twelve residues from enzymes TAG of $S$. typhi and $A$. baumannii for the mutational study. The calculated $\Delta \Delta \mathrm{G}$ values for 
mutation of twelve residues in both the enzymes are given in Table 4. The calculated change in $\Delta \mathrm{G}$ values for six of the twelve residues from TAG of $S$. typhi (only positive values) is in good agreement with experimental $3 \mathrm{~mA}$ excision rate $\left(10^{-3} \mathrm{~min}^{-1} \mathrm{mM}^{-1}\right)$ and as the experimental excision rate increases, the $\Delta \Delta \mathrm{G}$ values decrease (Supplementary Fig. SI-9). Similar pattern in the change in free energy values for the TAG of A. baumannii is also obtained. The calculated change in free energy values for the simultaneous mutations of residues Glu40 and Tyr18 is very high $(\sim 3.55 \mathrm{kcal} / \mathrm{mol})$, which supports that decrease in the stability upon mutation of these residues. There are two possible reasons for the loss of activity on mutation of residues Glu40 and Tyr18 ( 2.05 and $1.5 \mathrm{kcal} / \mathrm{mol}$; respectively). Firstly, due to replacement of polar and bulky 4-hydroxyphenyl side chain of tyrosine from electron rich aromatic active site by the hydrophobic methyl group of alanine may cause deformations in the perfectly shaped active site of TAG which results in positive free energy change and the loss of activity [41]. Second reason is the loss of H-bonds present at the Hoogsteen and Watson-Crick faces of the substrate $3 \mathrm{~mA}$, as known from our molecular docking analysis and the crystal structure $[41,46]$. The obtained large positive $\Delta \Delta G$ value $(\sim 2.05 \mathrm{kcal} / \mathrm{mol})$ for the residue Glu38Ala indicates that glutamic acid plays a major role in providing the binding specificity for $3 \mathrm{~mA}$. Similar to Cao and his co-workers [46], our calculated $\Delta \Delta \mathrm{G}$ values support that mutations of residues Trp6, Tyr13, Tyr16, Glu38, Gln41, Ser47, Thr160 and Gln167 in S. typhi TGA and homologous residues Trp8, Tyr15, Tyr18, Glu40, Gln43, Ser47, Thr162 and Gln169 in A. baumannii TGA modulate the enzymatic function by destabilizing the pocket geometry and interactions crucial for binding of substrate $3 \mathrm{~mA}$.

However, mutation of Trp6, Gly43, Leu44, Trp46 and Lys91 showed negative $\Delta \Delta \mathrm{G}$ values, predicting stabilizing effect of respective mutations. In the case of Trp6Ala and Trp46Ala mutations, the value of free energy change is contributed by van der Waals interactions and solvation terms. Mutations of Trp to Ala are energetically favourable because replacement of indole ring through methyl group at the $\beta$-position may impose rigidity, means mutation of Trp to Ala produces the rigidity in the active pocket and loss of conformational freedom could be adding to stability. Electron-rich side chains of Trp present at the binding pocket of TAG enzyme make $\pi-\pi$ stacking interactions with the electron-deficient nucleobase $3 \mathrm{~mA}$, needed for the enzyme activity. On mutation of Trp to Ala, the activity is lost because of the unavailability of the aromatic side chain to make $\pi-$ $\pi$ stacking interaction. The plug and wedge residues Gly43 and Leu44 are important for the 
DNA conformation stabilization during accommodation of extra helical nucleotide. The change in free energy values for both of Gly43 and Leu44 residues on mutation is negative demonstrating that these mutations impart stability in the TAG. In both the TAGs and in its related member AlkA, Leu is present at the respective position which is surrounded by hydrophobic residues. Due to which, substitution of Leu44 side chain (Leu44-Ala44) considerably increases the stability while sacrificing its functionality. The $\Delta \Delta \mathrm{G}$ values of mutation of residues are in agreement with literature data. Analysis of molecular interactions indicates how these residues play key role in the activity and how they help in the maintenance of pocket shape and environment suitable for $3 \mathrm{~mA}$ binding. Effects of mutations are more dramatic for the key catalytic residues and replacement of the residues holding the DNA appends stability pay off.

\section{Concluding remarks}

In the present study we have generated a three dimensional model structure of TAG from $A$. baumannii. Model structural analysis results show that TAG shares the Helix-hairpin-Helix domain as is characteristic of DNA binding protein. It shares a common catalytic site with the TAG from Salmonella typhi and hints that it has some unique features which are different from higher eukaryotes adenine DNA glycosylases and this makes it a potential target for drug design against $A$. baumannii and overcome the multi-drug resistance. The alignment of TAG sequences indicates that the key residues involved in polar interactions are conserved in query and all templates.

The recombinant A. baumannii TAG protein was cloned, expressed and purified from soluble fractions in two chromatographic steps. The molecular weight and oligomeric state was confirmed using size exclusion chromatography. The secondary structure characterization of native as well as substrate bound TAG was done from far UV-CD spectra, which shows the presence of properly folded secondary structure appropriate for the structural and functional studies. The agreement between the percentage of secondary structures predicted by molecular modeling and the secondary structure obtained by $\mathrm{CD}$ spectroscopy increases our confidence in the accuracy of the prepared TAG model. The involvement of active site Tyr in substrate recognition was characterized using CD-spectra which are in good agreement with molecular docking analysis. We believe that the results obtained in this study may unravel new horizons to understand the TAG structure-function relationships. This is the first report on A. baumannii TAG expression in E. coli. The 
detailed structure analysis provides the new pathway for the development of new inhibitors for the treatment of the infections caused by A. baumannii.

Analysis of experimental complexes and redocking methodology confirms that binding mode and H-bond pattern of various TAG-complexes are similar except for the Hbonds formed with Glu residue. The binding pose of inhibitors screened shows consistent pattern of stabilizing forces as noticed in redocked experimental complexes. TAG inhibitors (compounds 4, 6 and 7) can be used as starting points in the search for more potent and selective binding inhibitors against $\mathrm{HhH}$ family and may have capacity to inhibit TAG from other related species also, but enzyme inhibition assays are required to confirm this prediction. The molecular docking and CD analysis revealed that Glu40 and Tyr18 are conserved and catalytically important for the enzyme function. This was further confirmed by the large positive $\Delta \Delta \mathrm{G}$ value obtained from the mutagenesis experiments.

\section{Abbreviations}

3mA: 3-methyladenine

7mG: 7-methylguanine

AlkA: 3-methyladenine DNA glycosylase II

BER pathway: base excision repair pathway

TAG: 3-methyladenine DNA glycosylase I

\section{Acknowledgment}

JST thanks MHRD, New Delhi for a research fellowship. We are grateful to Professor

Prasad V. Bharatam, National Institute of Pharmaceutical Education and Research (NIPER), Mohali for his insightful comments and stimulating discussions.

\section{References}

[1] A.Y. Peleg, H. Seifert, D.L. Paterson, Acinetobacter baumannii: emergence of a successful pathogen, Clin. Microbiol. Rev. 21 (2008) 538-582. 
[2] L.L. Maragakis, T.M. Perl, Acinetobacter baumannii: epidemiology, antimicrobial resistance, and treatment options, Clin. Infect. Dis. 46 (2008) 1254-1263.

[3] D.R. Sullivan, J. Shields, G. Netzer, Fatal case of multi-drug resistant Acinetobacter baumannii necrotizing fasciitis, Am. J. Surg. 76 (2010) 651-653.

[4] M. Iacono, L. Villa, D. Fortini, R. Bordoni, F. Imperi, R.J. Bonnal, T. SicheritzPonten, G.D. Bellis, P. Visca, A. Cassone, A. Carattoli, Whole-genome pyrosequencing of an epidemic multidrug-resistant Acinetobacter baumannii strain belonging to the European clone II, Antimicrob, Agents Chemother. 52 (2008) 26162625.

[5] M.G. Smith, T.A. Gianoulis, S. Pukatzki, J.J. Mekalanos, L.N. Ornston, M. Gerstein, M. Snyder, New insights into Acinetobacter baumannii pathogenesis revealed by highdensity pyrosequencing and transposon mutagenesis, Genes Dev. 21 (2007) 601-614.

[6] C.Y. Lee, J.C. Delaney, M. Kartalou, G.M. Lingaraju, A. Maor-Shoshani, J.M. Essigmann, L.D. Samson, Recognition and processing of a new repertoire of DNA substrates by human 3-methyladenine DNA glycosylase (AAG), Biochemistry, 48 (2009) 1850-1861.

[7] K. Sakumi, M. Sekiguchi, Structures and functions of DNA glycosylases, Mut. Res. 236 (1990) 161-172.

[8] E. Seeberg, N.D. Clarke, G. Evensen, I. Kaasen, A.-L. Steinum, In: B. Myrnes, and H. Krokan, (eds), Repair of DNA lesions introduced by $N$-nitroso compounds, Norwegian University Press, Oslo, (1986) pp. 51-61.

[9] A.C. Drohat, K. Kwon, D.J. Krosky, J.T. Stivers, 3-methyladenine DNA glycosylase I is an unexpected helix-hairpin-helix superfamily member, Nat. Struct. Biol. 9 (2002) 659-664. 
[10] E.C. Friedberg, G.C. Walker, W. Siede, R.A. Schultz, DNA Repair and Mutagenesis, 2nd ed., ASM Press, Washington, D.C., 2006.

[11] S. Riazuddin, T. Lindahl, Properties of 3-methyladenine-DNA glycosylase from Escherichia coli, Biochemistry, 11 (1978) 2110-2118.

[12] S. Bhattacharya, P. Kumar, An in silico approach to structural elucidation of 3-deoxyD-arabino-heptulosonate 7-phosphate synthase from Arabidopsis thaliana: Hints for herbicide design, Phytochemistry, 73 (2012) 7-14.

[13] R. Guerois, J.E. Nielsen, L. Serrano, Predicting changes in the stability of proteins and protein complexes: a study of more than 1000 mutations, J. Mol. Biol. 320 (2002) 369-387.

[14] D. Singh, K.K. Sharma, M.S. Dhar, J.S. Virdi, Molecular modeling and docking of novel laccase from multiple serotype of Yersinia enterocolitica suggests differential and multiple substrate binding, Biochem. Biophys. Res. 449 (2014) 157-162.

[15] S. Kalyaanamoorthy, Y.-P.P. Chen, Modelling and enhanced molecular dynamics to steer structure-based drug discovery, Prog. Biophys. Mol. Bio. 114 (2014) 123-136.

[16] K.S. Hingorani, L.M. Gierasch, Comparing protein folding in vitro and in vivo: foldability meets the fitness challenge, Curr. Opin. Struct. Biol. 24 (2014) 81-90.

[17] S.F. Altschul, W. Gish, W. Miller, E.W. Myers, D.J. Lipman, Basic local alignment search tool, J. Mol. Biol. 215 (1990) 403-410.

[18] H.M. Berman, J. Westbrook, Z. Feng, G. Gilliland, T.N. Bhat, H. Weissig, I.N. Shindyalov, P.E. Bourne The protein data bank, Nuc. Acids Res. 28 (2000) 235-242.

[19] P. Gouet, E. Courcelle, D.I. Stuart, F. Metoz, ESPript: multiple sequence alignments in PostScript, Bioinformatics, 15 (1999) 305-308.

[20] A. Sali, T.L. Blundell, Comparative protein modeling by satisfaction of spatial restraints, J. Mol. Biol. 234 (1993) 779-815. 
[21] M.A. Marti-Renom, M.S. Madhusudhan, A. Fiser, B. Rost, A. Sali, Reliability of assessment of protein structure prediction methods, Structure, 10 (2002) 435-440.

[22] A. D. MacKerell, et al., All-atom empirical potential for molecular modelling and dynamics studies of proteins, J. Phys. Chem. B, 102 (1998) 3586-3616.

[23] B.R. Brooks, et al., CHARMM: A program for macromolecular energy minimization and dynamics calculations, J. Comp. Chem. 4 (1983) 187-217.

[24] R. Luthy, J.U. Bowie, D. Eisenberg, Assessment of protein models with threedimensional profiles, Nature, 356 (1992) 83-88.

[25] R.A. Laskowski, M.W. MacArthur, J. M. Thornton, Validation of protein models derived from experiment, Curr. Opin. Struct. Biol. 8 (1998) 631-639.

[26] R.W. Hooft, G. Vriend, C. Sander, E.E. Abola, Errors in protein structures, Nature, 381 (1996) 272-272.

[27] G.M. Morris, D.S. Goodsell, R.S. Halliday, R. Huey, W.E. Hart, R.K. Belew, A.J. Olson, Automated docking using a Lamarckian genetic algorithm and an empirical binding free energy function, J. Comput. Chem. 19 (1998) 1639-1662.

[28] B. Wallner, A. Elofsson, All are not equal: A benchmark of different homology modeling programs, Prot. Sci. 5 (2005) 1315-1327.

[29] P.K. Balasubramanian, A. Balupuri, G. Kothandan, S.J. Cho, In silico study of 1-(4phenylpiperazin-1-yl)-2-(1H-pyrazol-1-yl) ethanones derivatives as CCR1 antagonist: Homology modeling, docking and 3D-QSAR approach, Bioorg. Med. Chem. Lett. 24 (2014) 928-933.

[30] N. Tokuriki, F. Stricher, J. Schymkowitz, L. Serrano, and D.S. Tawfik, The stability effects of protein mutations appear to be universally distributed, J. Mol. Biol. 369 (2007) 1318-1332. 
[31] L.K. Wolf, New software and websites for the chemical enterprise, Chem. Eng. News, 87 (2009) 31-33.

[32] H. Inoue, H. Nojima, H. Okayama, E. coli competent cells and transformation, Gene, 96 (1990) 23-28.

[33] G. Bohm, R. Muhr, R. Jaenicke, Quantitative analysis of protein far UV circular dichroism spectra by neural networks, Protein Eng. 5 (1992) 191-195.

[34] X. Zhu, X.Yan, L.G. Carter, H. Liu, S. Graham, P.J. Coote, J. Naismith, A model for 3-methyladenine recognition by 3-methyladenine DNA glycosylase I (TAG) from Staphylococcus aureus, Acta Cryst. F, 68 (2012) 610-615.

[35] E. Krissinel, E. Henrick, Secondary-structure matching (SSM), a new tool for fast protein structure alignment in three dimensions, Acta Cryst. D, 60 (2004) 2256-2268.

[36] L. Romero, B. Trenor, P.-C. Yang, J. Saiz, C.E. Clancy, In silico screening of the impact of hERG channel kinetic abnormalities on channel block and susceptibility to acquired long QT syndrome, J. Mol. Cell. Cardiol. 72 (2014) 126-137.

[37] X. Dong, Y. Zhao, X. Huang, K. Lin, J. Chen, E. Wei, T. Liu, Y. Hu, Structure-based drug design using GPCR homology modeling: Toward the discovery of novel selective CysLT2 antagonists, Eur. J. Med. Chem. 62 (2013) 754-763.

[38] D. Siow, B. Wattenberg, The histone deacetylase-6 inhibitor tubacin directly inhibits de novo sphingolipid biosynthesis as an off-target effect, Biochem. Biophys. Res. Commun. 449 (2014) 268-271.

[39] B. Allison, S. Combs, S. DeLuca, G. Lemmon, L. Mizoue, J. Meiler, Computational design of protein-small molecule interfaces, J. Struct. Biol. 185 (2014) 193-202.

[40] A. Banerjee, W.L. Santos, G.L. Verdine, Structure of a DNA glycosylase searching for lesions, Science, 311 (2006) 1153-1157. 
[41] A.H. Metz, T. Hollis, B.F. Eichman, DNA damage recognition and repair by 3methyladenine DNA glycosylase I (TAG), EMBO J. 26 (2007) 2411-2420.

[42] K. Kwon, C. Cao, J.T. Stivers, A novel zinc snap motif conveys structural stability to 3-methyladenine DNA glycosylase I, J. Biol. Chem. 278 (2003) 19442-19446.

[43] J.A. Zitzewitz, O. Bilsel, J. Luo, B.E. Jones and C.R. Matthews, Probing the Folding Mechanism of a Leucine Zipper Peptide by Stopped-Flow Circular Dichroism Spectroscopy, Biochemistry, 34 (1995) 12812-12855.

[44] Norma J. Greenfield, Determination of the folding of proteins as a function of denaturants, osmolytes or ligands using circular dichroism, Nat Protoc. 1 (2006) 27332741.

[45] S. D. Pawlak, M.Radlinska, A. A. Chmiel, J. M. Bujnicki, K. J. Skowronek, Inference of relationships in the 'twilight zone' of homology using a combination of bioinformatics and site-directed mutagenesis: a case study of restriction endonucleases Bsp6I and PvuII, Nuc. Acids Res. 33 (2005) 661-671.

[46] C. Cao, K. Kwon, Y.L. Jiang, A.C. Drohat, J.T. Stivers, Solution structure and base perturbation studies reveal a novel mode of alkylated base recognition by 3methyladenine DNA glycosylase I, J. Biol. Chem. 278 (2003) 48012-48020. 


\section{Legends for Tables and Figures}

Fig. 1. Sequence alignment and secondary structure prediction of the enzymes; query (Accession no. YP_001848289.1) and PDB id: 2OFK_A.

Table 1 Summary of structural validation programs and parameters values for models and template (pdb id. 2OFK_A). Initial model (model obtained from MODELLER 9v12), minimized model (model after minimization) and repaired model (model obtained after FoldX repair function) (labelled residues means residues having bad torsions).

Fig. 2. Structural alignment of the enzymes; predicted in silico TAG model (coloured green) and template (PDB id: 2OFK_A) (coloured cyan) (A) Complete TAG model structure. (B) Residues lining the model binding pocket superimposed on experimental residues of binding pocket.

Fig. 3. Purification and molecular mass determination of TAG (A) Size exclusion chromatography profile of TAG analysis of major peak (using Hi-Load Superdex-200 16/60 column, $\mathrm{V}_{\mathrm{o}}=45 \mathrm{ml}$ and flow rate 0.5 $\mathrm{ml} / \mathrm{min}$ ). (B) SDS-PAGE analysis of major peak fractions show the protein (TAG) purified to homogeneity.

Fig. 4. Far-UV Circular Dichroism analysis of TAG alone (green) and after substrate 3mA binding (blue) in 25 $\mathrm{mM}$ sodium phosphate buffer at $20^{\circ} \mathrm{C}$. (B) Near-UV CD spectra of TAG alone (green) and after substrate $3 \mathrm{~mA}$ binding. (C) Change in ellipticity with addition of 10, 50,100, 200, 300, 400, 500 and $600 \mu \mathrm{M}$ of substrate $3 \mathrm{~mA}$ monitored at CD signal $222 \mathrm{~nm}$. (D) Change in ellipticity monitored at CD signal $222 \mathrm{~nm}$ as a function of temperature.

Table 2. Binding energies ( $\mathrm{kcal} / \mathrm{mol}$ ), RMSD values and binding interactions (Active site residues involved in the H-bond, Hydrophobic interactions) of experimental TAG complexes determined using Autodock 4.2.

Fig. 5. (A) Enzyme active site showing the residues forming direct interactions with experimental (cyan) and redocked (green) poses of substrate $3 \mathrm{~mA}$. (B) Active site showing residues crafting H-bonds with redocked 3mA. (C) TAG (model) active site residues making H-bonds with docked 3mA. (D) The predicted docking conformation (stick representation) of inhibitors superimposed on each other at the model binding pocket (Red arrow point towards the mouth of active site).

Table 3. Binding affinities ( $\mathrm{kcal} / \mathrm{mol})$, and $\mathrm{H}$-bond forming active site residues of the best ten compounds out of 550 compounds obtained from ZINC database having at least $60 \%$ structure similarity with the substrate $3 \mathrm{~mA}$. The Drug likeness score is given (higher drug likeness score designates the compound to be active drug).

Table 4. Mutational studies of the residues that are important for the enzyme activity, calculation of $\Delta \Delta G_{c a l}(W T$ Mut) values are given for model as well as template. Calculated $\Delta \Delta G_{c a l}(W T-M u t)$ values are compared with the experimental $3 \mathrm{~mA}$ excision rate. 
Table 1 Summary of structural validation programs and parameters values for models and template (pdb id. 2OFK_A). Initial model (model obtained from MODELLER 9v12), minimized model (model after minimization) and repaired model (model obtained after FoldX repair function) (id: lldbpmi6whn4dfl5v; Model Archive doi: $m a$ a6bjp).

\begin{tabular}{llcccc}
\hline \multirow{2}{*}{ Server } & \multicolumn{1}{c}{ Parameters } & Initial model & $\begin{array}{c}\text { Minimized } \\
\text { model }\end{array}$ & $\begin{array}{c}\text { FoldX } \\
\text { repaired } \\
\text { model }\end{array}$ & Template \\
\hline \multirow{2}{*}{ PROCHECK } & Residues in core, Allowed & $91.4 \%, 8.6 \%$ & $88.1 \%, 10.7 \%$ & $91.1 \%, 8.9 \%$ & $92.6 \%, 7.4 \%$ \\
& $\begin{array}{l}\text { Generously allowed regions } \\
\text { Labelled residues }\end{array}$ & $0.0 \%$ & $0.6 \%$ & $0.0 \%$ & $0.0 \%$ \\
WHATCHECK & Residues having bad & $1,2,39,50$ & $1,2,26,27$, & $1,2,39,50$ & $1,2,39,48$, \\
& stereochemical parameters & & $39,47,50$ & & 53 \\
VERIFY3D & Residues having averaged & $74.33 \%$ & $84.43 \%$ & $88.24 \%$ & $95.69 \%$ \\
& 3D-1D score > 0.2 & & & & \\
ERRAT & Overall quality factor & $85.39 \%$ & $91.70 \%$ & $91.87 \%$ & $92.39 \%$ \\
PDBeFold & Q score & 0.94 & 0.94 & 0.94 & \\
& RMSD & $0.30 \AA$ & $0.68 \AA$ & $0.19 \AA$ & \\
\hline
\end{tabular}


Table 2. Binding energies (kcal/mol), RMSD values and binding interactions (Active site residues involved in the H-bond, Hydrophobic interactions) of experimental TAG complexes determined using Autodock 4.2.

\begin{tabular}{cccccc}
\hline PDB id & Binding energy & IC50 (experimental) & RMSD $(\AA)$ & H-bond & Hydrophobic Int. \\
\hline 2OFI & -4.98 & $1.5 \pm 0.3 \mathrm{mM} /$ & 1.67 & Y16, E38 & W6, W46, S164 \\
1PVS & -6.06 & & 1.52 & Y239, L25 & W218 \\
1PU7 & -5.16 & & 0.66 & - & W24, P45, L211 \\
1PU8 & -6.98 & $50 \pm 10 \mu \mathrm{M}$ & 1.09 & L211 & W24, P26 \\
1P7M & -5.18 & $1.5 \pm 0.3 \mathrm{mM}$ & 2.12 & Y16, E38 & W46, W21, Y13 \\
1AIA & -4.76 & & 2.06 & Y16, E38 & W46, P6 \\
1AI5 & -4.46 & & 1.96 & E38 & W46, A168 \\
\hline
\end{tabular}


Table 3. Binding affinities ( $\mathrm{kcal} / \mathrm{mol}$ ), and H-bond forming active site residues of the best ten compounds out of 550 compounds obtained from ZINC database having at least $60 \%$ structure similarity with the substrate $3 \mathrm{~mA}$. The Drug likeness score is given (higher drug likeness score designates the compound to be active drug).

\begin{tabular}{|c|c|c|c|c|}
\hline $\begin{array}{c}\text { S no. \& } \\
\text { Name }\end{array}$ & Compound structure & $\begin{array}{l}\text { Binding } \\
\text { affinity }\end{array}$ & $\begin{array}{c}\text { Residues } \\
\text { (No. of H-bonds) }\end{array}$ & $\begin{array}{l}\text { Drug likeness } \\
\text { score }\end{array}$ \\
\hline $\begin{array}{c}\text { 3mA } \\
\text { 3-methyl-3H-purin-6- } \\
\text { amine }\end{array}$ & & -4.98 & $\begin{array}{l}\text { Y16, E38 } \\
\text { (3-bonds) }\end{array}$ & - \\
\hline $\begin{array}{c}1 \\
(6 S, 8 S)-8-[(E)-2- \\
\text { phenylethenyl]- } \\
2,3,6,7,8,9- \\
\text { hexahydro-1H-purin- } \\
\text { 6-amine }\end{array}$ & & -8.01 & $\begin{array}{c}\text { Y15,S47, W48 } \\
\text { (3-bonds) }\end{array}$ & -0.09 \\
\hline $\begin{array}{c}\mathbf{2} \\
(6 R, 8 R)-8-(3- \\
\text { methylphenyl)- } \\
2,3,6,7,8,9- \\
\text { hexahydro-1H-purin- } \\
\text { 6-amine }\end{array}$ & & -7.90 & $\begin{array}{c}\text { Y15 } \\
\text { (2-bonds) }\end{array}$ & 0.73 \\
\hline $\begin{array}{c}\mathbf{3} \\
\text { pyrimido[5,4- } \\
\text { g]pteridine- } 2,4,6,8- \\
\text { tetramine }\end{array}$ & $\mathrm{NH}_{2}$ & -7.62 & $\begin{array}{l}\text { W8, Y15, Q169 } \\
\text { (6-bonds) }\end{array}$ & -1.79 \\
\hline $\begin{array}{c}\mathbf{4} \\
(6 S, 8 R)-8-(4- \\
\text { phenylphenyl)- } \\
2,3,6,7,8,9- \\
\text { hexahydro-1H-purin- } \\
\text { 6-amine }\end{array}$ & & -7.61 & $\begin{array}{l}\text { Y15, E40 } \\
\text { (2-bonds) }\end{array}$ & 1.03 \\
\hline $\begin{array}{c}\mathbf{5} \\
\text { N1-[(6R)-2,3,6,7,8,9- } \\
\text { hexahydro-1H-purin- } \\
\text { 6-yl]benzene-1,3- } \\
\text { diamine }\end{array}$ & & -7.57 & $\begin{array}{l}\text { Y15, E40, Q43 } \\
\text { (6-bonds) }\end{array}$ & -0.74 \\
\hline $\begin{array}{c}\mathbf{6} \\
(2 R, 4 S)-2- \\
{[(1 R, 3 S, 5 R, 7 S)-} \\
\text { adamantan-2-yl]- } \\
2,3,4,7,8,9- \\
\text { hexahydro-1H-purin- } \\
\text { 6-amine }\end{array}$ & & -7.55 & $\begin{array}{l}\text { W8, Y15 } \\
\text { (3-bonds) }\end{array}$ & 1.73 \\
\hline $\begin{array}{c}7 \\
(6 R, 8 S)-8 \text {-benzyl- } \\
2,3,6,7,8,9- \\
\text { hexahydro- } 1 H \text {-purin- } \\
\text { 6-amine }\end{array}$ & & -7.54 & $\begin{array}{c}\text { Tyr15 } \\
\text { (2-bonds) }\end{array}$ & 1.63 \\
\hline $\begin{array}{c}\mathbf{8} \\
(6 S)-6-(2- \\
\text { phenylhydrazin-1-yl)- } \\
2,3,6,7,8,9- \\
\text { hexahydro- } 1 H \text {-purine }\end{array}$ & & -7.52 & $\begin{array}{l}\text { Y15, Y134 } \\
\text { (3-bonds) }\end{array}$ & 0.43 \\
\hline
\end{tabular}




\begin{tabular}{|c|c|c|c|c|}
\hline $\begin{array}{c}\text { 9 } \\
\text { (6R)-N-cyclododecyl- } \\
\text { 2,3,6,7,8,9- } \\
\text { hexahydro-1H-purin- } \\
\text { 6-amine }\end{array}$ \\
\hline $\begin{array}{c}\mathbf{1 0} \\
\begin{array}{c}(2 R, 4 S, 6 S, 8 R)- \\
1 H, 2 H, 3 H, 4 H, 5 H, 6 H, \\
7 H, 8 H, 9 H, 10 H- \\
\text { pyrimido[5,4- } \\
g] \text { pteridine-2,4,6,8- } \\
\text { tetramine }\end{array}\end{array}$
\end{tabular}


Table 4. Mutational studies of the residues that are important for the enzyme activity, calculation of $\Delta \Delta G_{\text {cal (WT-Mut) }}$ values are given for model as well as template. Calculated $\Delta \Delta G_{\text {cal (WT-Mut) }}$ values are compared with the experimental $3 \mathrm{~mA}$ excision rate.

\begin{tabular}{ccccc}
\hline $\begin{array}{c}\text { Model } \\
\text { Residue }\end{array}$ & $\begin{array}{c}\boldsymbol{\Delta \Delta G} \\
(\boldsymbol{k c a l} / \mathbf{m o l})\end{array}$ & $\begin{array}{c}\text { Template } \\
\text { Residue }\end{array}$ & $\begin{array}{c}\boldsymbol{\Delta A G} \\
(\boldsymbol{k c a l} / \mathbf{m o l})\end{array}$ & $\begin{array}{c}\text { 3mA Excision rate } \\
\mathbf{1 0}^{-\mathbf{3}} \mathbf{m i n}^{-\mathbf{1}} \boldsymbol{\mu} \mathbf{M}^{-\mathbf{1}}\end{array}$ \\
\hline W8A & -2.61 & W6A & -3.02 & $29.2 \pm 16.9$ \\
Y15F & +1.08 & Y13F & +1.07 & $54.7 \pm 39.3$ \\
Y18F & +1.53 & Y16F & +1.33 & $19.0 \pm 4.60$ \\
E40A & +2.05 & E38A & +2.13 & $0.7 \pm 0.1$ \\
Q43A & +0.93 & Q41A & +0.60 & $36.2 \pm 3.1$ \\
G45L & -2.09 & G43L & -1.42 & $2.5 \pm 0.8$ \\
L46A & -2.86 & L44A & -1.03 & $6.5 \pm 4.4$ \\
S47A & +0.73 & S47A & +0.46 & $230 \pm 7.8$ \\
W48A & -2.48 & W46A & -4.12 & $20.7 \pm 7.4$ \\
K93A & -2.11 & K91A & -1.47 & $26.9 \pm 1.5$ \\
T162V & +0.34 & T160V & +0.28 & $273.8 \pm 68.3$ \\
Q169A & +0.64 & Q167A & +0.85 & $107.2 \pm 55.7$ \\
\hline
\end{tabular}


Fig. 1

Tт vevelieve

severeverer

reece rever $\pi^{23}$

2005

ee

verever

TT

$30 \quad 40$ 5 !

50

70

80

2 OFK
Query

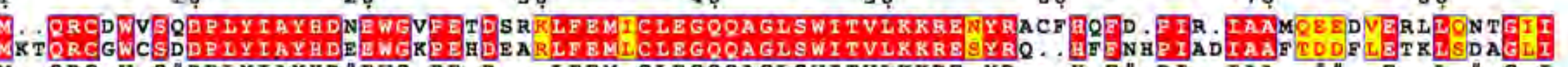

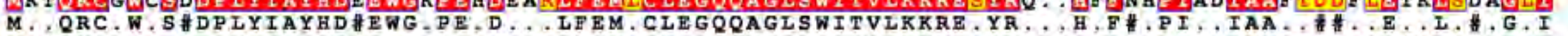

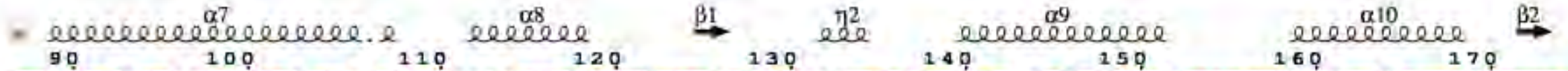

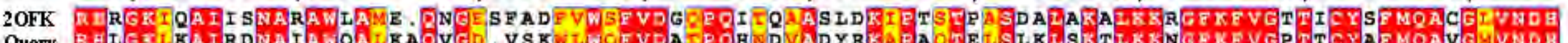

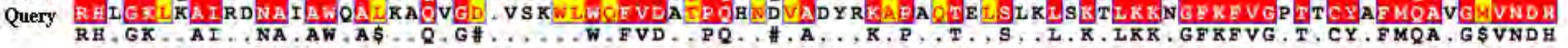

TT TT

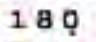

2OFK ITGC.ECRP

Query ENDCQEKAS

... C. F... 


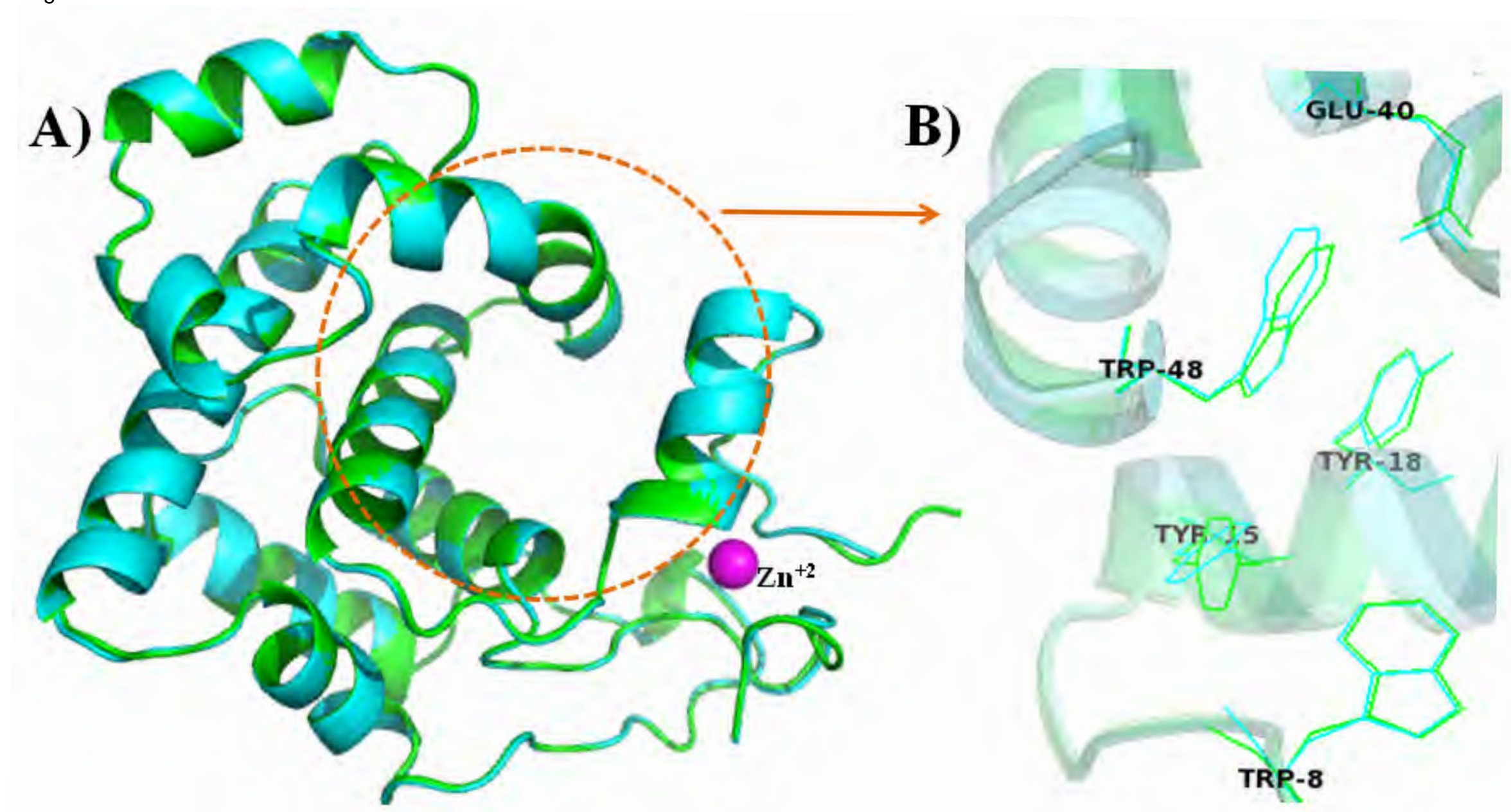

Fig. 2

TRP-8 
Fig. 3

700

$$
90.45 \mathrm{~mL}
$$

(A) 600

(B)

है 500

$\circ$

Elution volume (mL) 
Fig. 5

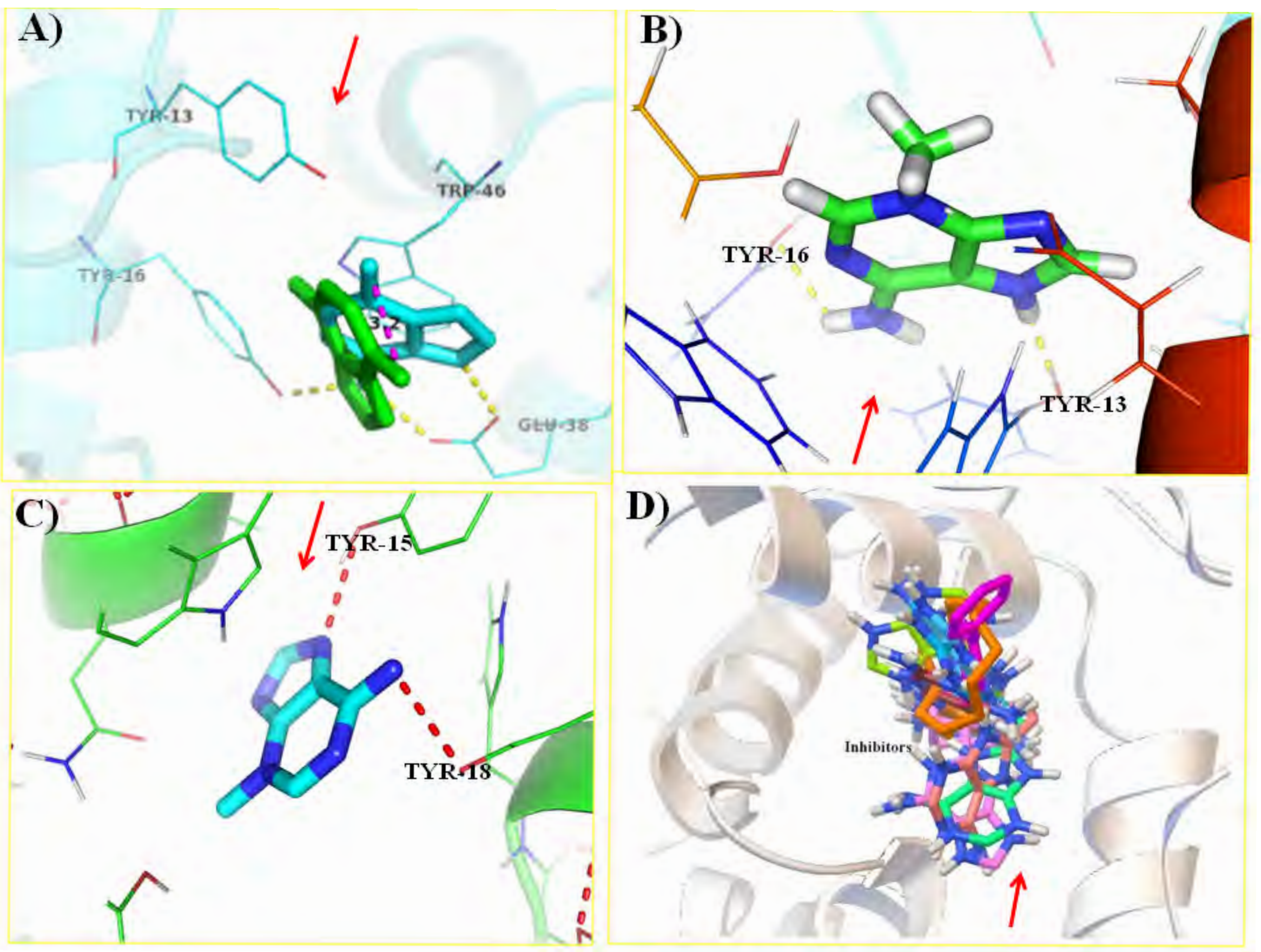


Fig. 4
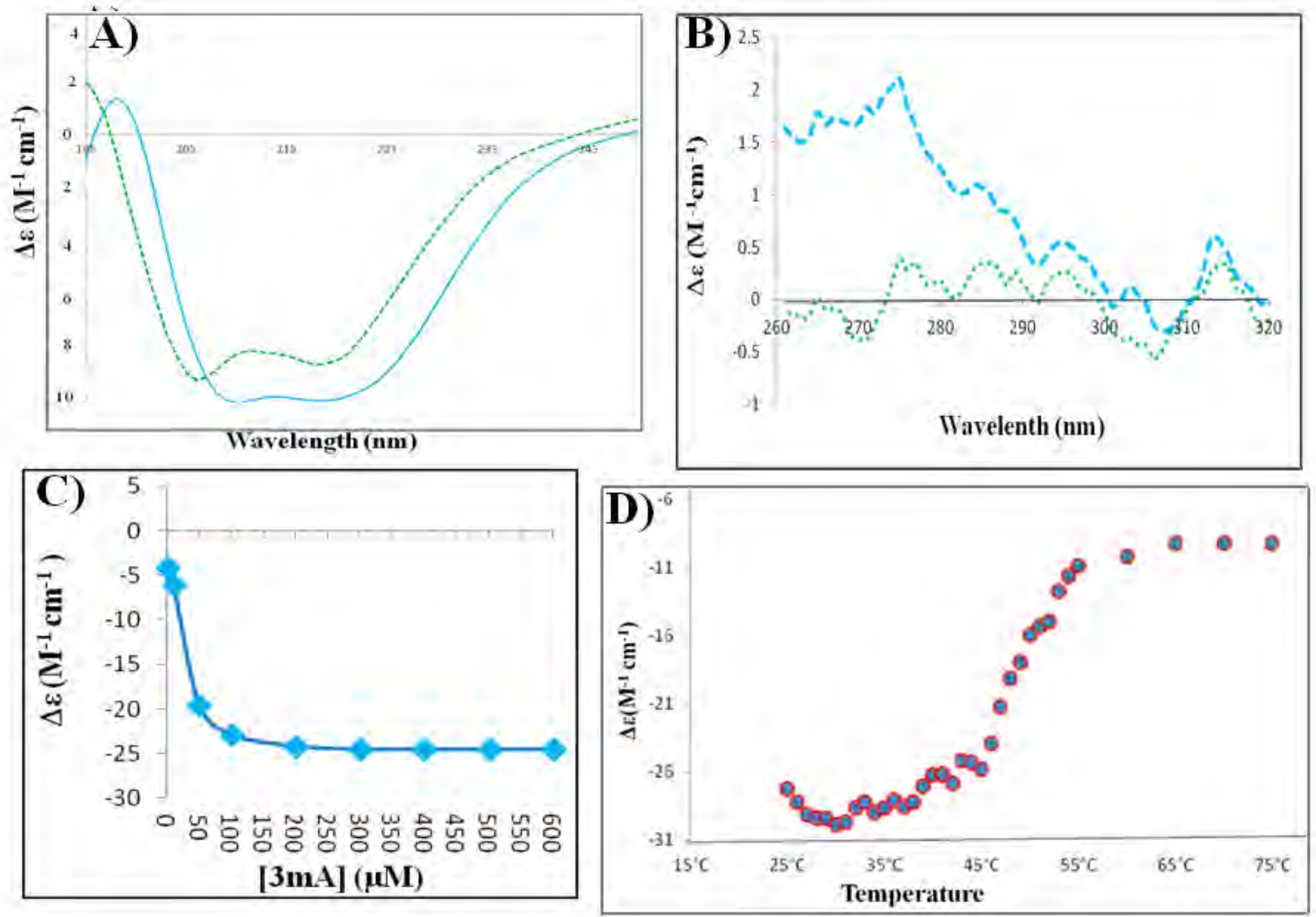